\title{
Monitoring of horizontal subsurface flow constructed wetlands for tertiary treatment of municipal wastewater
}

\author{
Karim Ergaieg $^{1}$ (D) Mohamed Haythem Msaddek $^{2} \cdot$ Amjad Kallel $^{3} \cdot$ Ismail Trabelsi $^{4}$
}

Received: 23 July 2021 / Accepted: 8 September 2021 / Published online: 22 September 2021

(C) Saudi Society for Geosciences 2021

\begin{abstract}
This paper explores the feasibility of the electrical resistivity (ER) method as non-invasive technique to detect dysfunctions of full-scale tertiary wastewater treatment wetlands, such as clogging, that ultimately limit the system lifetime and performance. ER measurements were carried out according to the Werner's method on two (overloaded) horizontal subsurface wetlands (HSFCW1 and HSF-CW2) operated in parallel since the end of 2017, while still achieving satisfactory treatment efficiencies. Layered clog-induced preferential flow pathways through the HSF-CW beds and premature deterioration of the wetland's liner with a possible development of dead zones associated with a low/heterogeneous density of vegetation could be confirmed by analysis of ER profiles. These results suggest that the ER method is a promising and feasible technique, as simplified then adapted/adopted to local context, for better monitoring and assessment of treatment wetlands with early process failure.
\end{abstract}

Keywords Horizontal subsurface wetlands $\cdot$ Tertiary wastewater treatment $\cdot$ Monitoring $\cdot$ Clogging $\cdot$ Electrical resistivity method

\section{Introduction}

Constructed wetlands (CWs) with horizontal subsurface flow (HSF) represent a suitable and low-cost technology commonly used for wastewater treatment in small communities, but also widely used in large plants as tertiary (polishing) treatment following secondary biological treatment (Cooper 2009). Used as tertiary treatments, HSF-CW systems are able to further remove suspended solids, pathogens, or nutrients, among other pollutants, allowing both water and nutrient reclamation (Thalla et al. 2019). For decades, HSF constructed

Responsible Editor: Biswajeet Pradhan

Karim Ergaieg

karim.ergaieg@inat.u-carthage.tn

1 Laboratory of Ecosystems and Aquatic Resources, National Agronomic Institute of Tunisia (INAT), University of Carthage, 1082 Tunis, Tunisia

2 Department of Geology, Faculty of Sciences of Tunis (FST), University of Tunis El Manar, 2092 Tunis, Tunisia

3 Laboratory of Water, Energy and Environment, Sfax National School of Engineering, University of Sfax, Sfax, Tunisia

4 Centre de Recherches et Technologies des Eaux, Laboratoire de Traitement et Valorisation des Rejets Hydriques, 13 BP 273, 8020 Soliman, Tunisia wetlands have been successfully used around the world in treating different types of wastewaters and various pollutants, with thousands of units implemented worldwide, showing in most cases satisfactory performances (Ghimire et al. 2019). However, the major operational concern to date is clogging, which is an inevitable process that, depending on its extent, may affect the service life and treatment efficiency of such systems (Vasconcellos et al. 2019).

HSF-CW systems consist of waterproof basins, filled with porous media (generally gravel beds), planted with emergent macrophytes (such as Phragmites australis), in which wastewater flows horizontally. In the filtration beds, pollution is removed by a combination of microbial degradation and chemical and physical processes (Vymazal 2010). Clogging occurs when the pore spaces in the filter media of a HSF-CW bed are filled with either organic or inorganic solids, thus limiting the contact area and time between the biofilm (microbial) associated with plants' root systems and the water to be treated (Knowles et al. 2011). In a HSF-CW system operated ordinarily, wastewater is introduced at the inlet zone and slowly flows through the granular (or porous) filtration medium below the bed surface in a more or less horizontal path until it reaches the outlet zone, where it is collected and discharged (Brix 1987). With the operation of the system, the void space is potentially prone to clogging by the gradual accumulation of substrate comprising suspended solids, 
biological films, chemical precipitates, plant residues, etc. (Miranda et al. 2017; De Matos et al. 2018). In general, the gradual net accumulation of this mixture in pore spaces yield surface overland flow with a clogging of $\mathrm{CW}$ (Liu et al. 2018a; Vymazal 2018; Vasconcellos et al. 2019).

According to the IWA task group (2017), hydraulic and solids loading rates that are at the upper limit of recommended values for the design and operation of HSF-CW systems have been suggested as the main factors leading in most cases to rapid clogging and long-term failure. However, the adoption of suitable filtering materials and applied loads, together with system maintenance, may mitigate this process (Kadlec and Wallace 2009; Vymazal 2018). Furthermore, when wastewater flows through the porous medium of HSF-CW, the clogging process is often inevitable over time (De Matos et al. 2018; Vymazal 2018). So far, current practices for avoiding or managing substrate clogging, whether preventative measures (e.g., intermittent operation, reducing hydraulic load) or restorative measures (e.g., cleaning and changing areas that exhibit clog-induced hydraulic problem), could only relatively mitigate and inform, with lack of accuracy, the actual extent of the clogging process, respectively. Over the past decade, the cumulative issues dealing with void space clogging have gained increasing attention worldwide (Wang et al. 2021), and adapted methods to the local context towards clogging detection as well as anomalies/areas of interest such as lateral losses or dead zones were usually the key challenge (Casas et al. 2012; Liu et al. 2018a).

The available clogging detection methods tested in the last 10 years (e.g., hydraulic conductivity measurement, tracer testing, clogging matter characterization) are usually complex and expensive or time-consuming to enable actual and wide largescale application of these techniques, or to ensure sustainable monitoring of operational wetlands (Knowles et al. 2010; Nivala et al. 2012; Aiello et al. 2016; De Matos et al. 2018). In addition, the techniques mentioned above are mostly invasive and involve some disturbance of the sample (area). Some limitations in the monitoring of clogging may be overcome by use of geophysical techniques, which rely on measurements of electric and electromagnetic properties of the porous medium. These methods are generally less disruptive than techniques that require extracting samples or taking the system offline. Non-destructive methods such as electrical resistivity tomography (ERT) are already used in many fields. Recently, Vanella et al. (2018) evaluated the use of small-scale ERT as a promising tool to identify soil-root interaction during deficit irrigation. Greggio et al. (2018) recently reported that the ERT methodology allows for fast data acquisition and it also permits the study of the evolution in time of freshwater availability. Turki et al. (2019) reported the applicability of ERT as a promising technique for the survey of soil organic matter content monitoring, dispersion, and assessment. Recent research has shown that ERT is also useful in monitoring HSF-CW systems, especially for identifying clogging (Marzo et al. 2018). Furthermore, it has recently been reported that the electrical resistivity method could be a relevant candidate to approach clogging issues of subsurface flow wetlands, as described by lab-scale experiments of Liu et al. (2018a). The same authors have studied in the laboratory the clogging in horizontal subsurface flow constructed wetland using the resistivity method, and highlighted the effect of clogging on apparent resistivity. This method has the advantages of being non-destructive, lowcost, and time-saving, and could be a potential technique to detect first HSF-CW operation anomalies based on the apparent resistivity distributions in wetland beds.

In Tunisia, the use of constructed wetlands dates back to the early 2000s, yet to date this treatment technology has only been reported for a handful of laboratory experiments, and pilot and large-scale systems (Keffala and Ghrabi 2005; Ghrabi et al. 2011; Khouja et al. 2019). However, the assessment of wetland performance is often limited to monitoring water quality and pollutant removal efficiency. Besides, clogging issues or possible operation failures dealing with critical design features are not yet sufficiently highlighted or explored, even in cases where signs of clogging are noticeable. An important manifestation of the clogging process is when the increased head loss results in surface overland flow (De Paoli and von Sperling 2013), and can ultimately limit the lifetime of the system as well as the possible reduction in treatment efficiency (Vasconcellos et al. 2019). In the literature, there are few studies which cover both wetland treatment systems over many years of operation and address the likely influence of clogging on the performance of full-scale treatment wetlands (Vymazal 2019; Vasconcellos et al. 2019). This is endorsed by Vymazal (2018), who stated that surface runoff is considered a system failure and that there has been no report on evaluating the effect of clogging on a long-term treatment for the removal of commonly monitored parameters such as organic matter (measured as BOD and COD) and total suspended solids (TSSs).

The objective of the present study is to compare the performances of two full-scale horizontal subsurface flow constructed wetlands (HSF-CW units: HSF-CW1 and HSF-CW2) for tertiary wastewater treatment. Both planted with Phragmites australis (common reeds) and operated in parallel from the outset, the HSF-CW units (reed beds) were primarily designed to remove organics and solids from municipal secondary effluents for reuse application. The distinguishing feature of our work is that it relates both to the first full-scale decentralized treatment wetlands set up in Tunisia for wastewater treatment and reuse (design features, performance, operation, and maintenance gaps), and to the feasibility of the electrical resistivity method for in situ monitoring of HSF-CW units and the detection of possible premature clogging. The focus of this case study is to elucidate the factors or design/operating features of reed beds, currently suspected of being clogged, and which could play a role in the premature process failure. 


\section{Materials and methods}

\section{Description of treatment wetlands}

Two parallel full-scale horizontal subsurface flow constructed wetlands (HSF-CW1 and HSF-CW2: HSF-CW units, Figure 1a) were completed at the end of 2017 in the periurban forest area of Sidi Amor located in northern Tunisia $\left(36^{\circ} 55^{\prime}\right.$ $\left.45.00^{\prime \prime} \mathrm{N} 10^{\circ} 10^{\prime} 8.00^{\prime \prime} \mathrm{E}\right)$. The elevation of the site is $98 \mathrm{~m}$, semi-arid Mediterranean climate. The horizontal subsurface flow system (HSF-CW) was designed and built as part of a hybrid constructed wetland plant (HSF-CW combined with a maturation pond) for tertiary treatment of municipal wastewater prior to reuse (Ergaieg and Ben Miled 2021). The HSF-CW system was designed according to the commonly used method of Kadlec and Knight (1996), with a treatment capacity of 520 $\mathrm{m}^{3} /$ day, while the loading rate actually applied was far lower, around an average of $363 \mathrm{~m}^{3} /$ day, during the first 3 years of
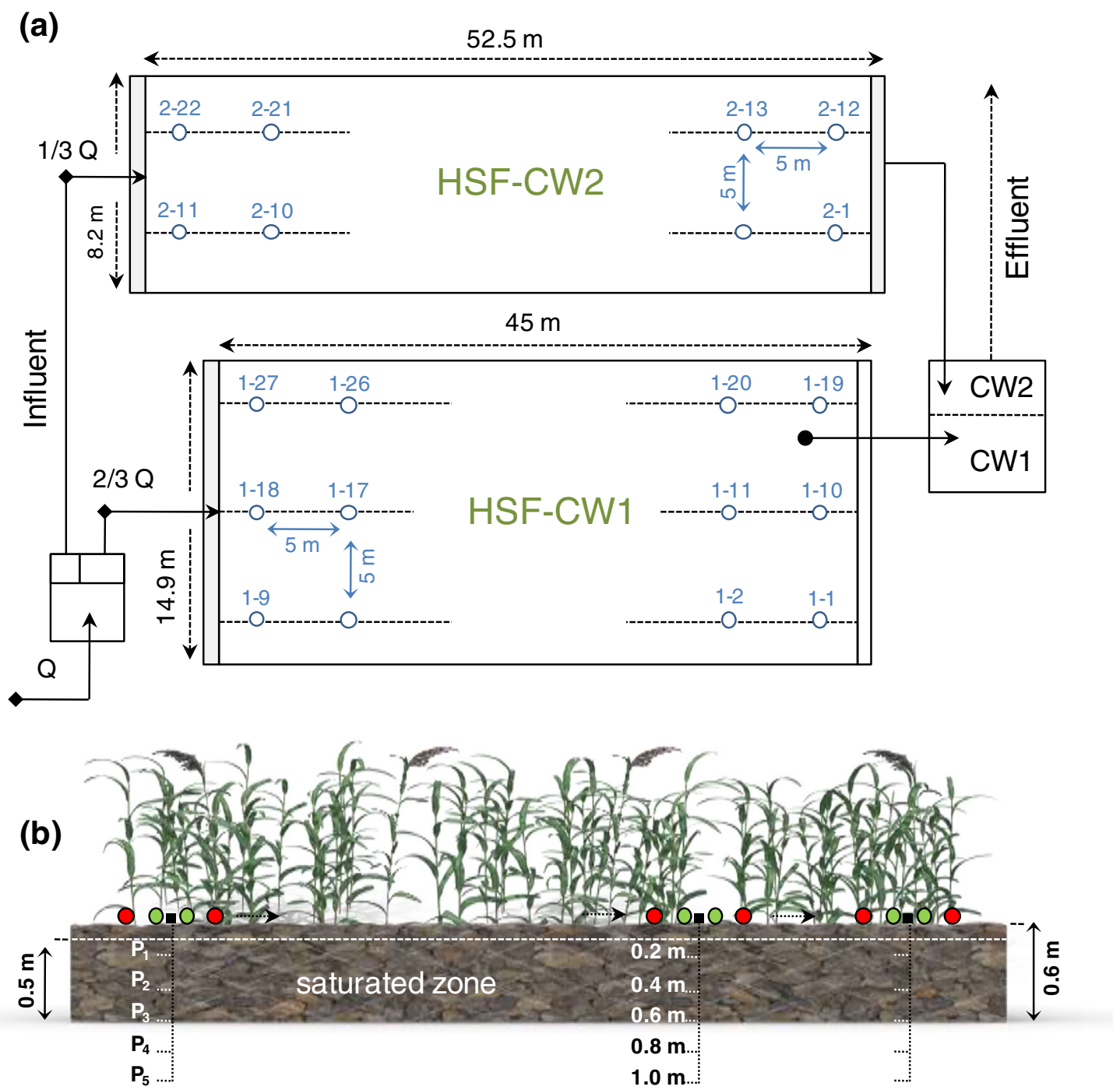

$$
\begin{aligned}
& P_{5}=1.0 m, a_{5}=1.333 m \\
& P_{4}=0.8 m, a_{4}=1.066 m \\
& P_{3}=0.6 m, a_{2}=0.800 m \\
& P_{2}=0.4 m, a_{2}=0.533 m \\
& P_{1}=0.2 m, a_{1}=0.266 m
\end{aligned}
$$

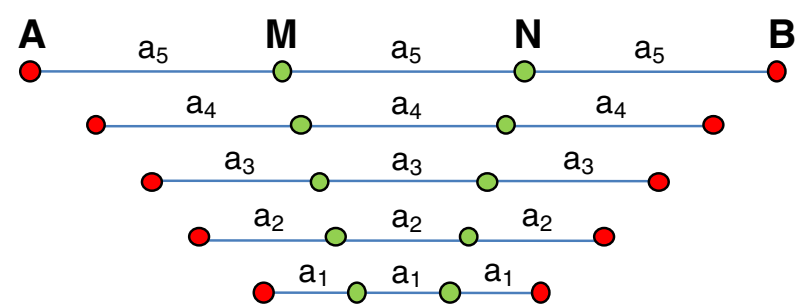

Fig. 1 Layout of the existing horizontal-flow HSF-CW units: a HSFCW1 and HSF-CW2, b vertical electrical survey using AMNB Wenner array; the solid arrows indicate the treated/reclaimed wastewater flow direction; Q: wastewater inflow to HSF-CW units; CW1: HSF-CW1 effluent; CW2: HSF-CW2 effluent; blue numbering indicates electrical survey points carried out overall at five depths in both wetland systems; ai: spacing between the AMNB electrodes; Pi: depth of investigation 
operation. The treatment wetland is supplied by a part of secondary effluents from municipal wastewater treatment plants located upstream and routed through a transfer network. The influent to constructed wetlands was not submitted to prior pretreatment (not considered in the initial design). The wetland bed surfaces are not identical, given the on-site land suitability; thus, one occupies $670 \mathrm{~m}^{2}$ (HSF-CW1) and the other $430 \mathrm{~m}^{2}$ (HSF-CW2). Each wetland cell was planted with common reeds, Phragmites australis. The substrate wetland consists of gravel (grain size Ø: 4-8 mm), a depth of $0.60 \mathrm{~m}$, and porosity of $38 \%$. A flow distributor device allows the repartition of the incoming-flow rate to each unit in the wetland according to a 1/3-2/3 ratio, respectively, for HSF-CW2 and HSF-CW1. During the study period, HSF-CW2 and HSF-CW1 were respectively operated at average hydraulic and organic loads (HLR, OLR) of $121 \mathrm{~m}^{3} /$ day and $34.66 \mathrm{~g} \mathrm{COD} / \mathrm{m}^{2} /$ day, and $242 \mathrm{~m}^{3} /$ day and $44.49 \mathrm{~g} \mathrm{COD} / \mathrm{m}^{2} /$ day. Each HSF-CW unit was fed separately by a perforated inlet pipe (Ø $120 \mathrm{~mm}$ ) located upstream along the width of a gabion zone to allow a uniform distribution of the wastewater across the constructed wetland beds. The horizontal flow systems have a bottom $3 \%$ slope to facilitate the passage of the effluent by natural gravity. Wastewater were discharged by means of a perforated pipe (Ø $120 \mathrm{~mm}$ ) located along the bottom width of HSF-CW2 outlet and a nozzle placed at the boundary of HSF-CW1 outlet. Treated effluents are mixed at the output of the HSF-CW system and then routed toward a maturation (polishing) pond for complementary treatment; since it is not the objective of this paper, this would not be further dealt with.

\section{Water quality monitoring}

In this study, TSS, biochemical oxygen demand (BOD), and chemical oxygen demand (COD) were monitored during the first 3 years of operation $(2018,2019$, and 2020) at the inlet and outlet of each HSF-CW unit. This corresponds to three control points: HSF-CW units' inlet, HSF-CW1 outlet, and HSF-CW2 outlet. Water quality analysis was performed once every two calendar months (i.e., six times per year) according to the standard methods (APHA/AWWA/WEF 2005). The treatment efficiency achieved by HSF-CW units in the removal of suspended particles and organic matter and the applied surface loading rate (SLR, $\mathrm{g} / \mathrm{m}^{2} /$ day) to each unit was respectively evaluated as follows (Herrera-Melián et al. 2020):

Removal $(\%)=\left(\frac{C_{i}-C_{o}}{C_{i}}\right) \times 100$

$S L R=\frac{C_{i} \times Q}{S}$

where $C_{\mathrm{i}}$ is the concentration $(\mathrm{mg} / \mathrm{l})$ in the influent; $C_{\mathrm{o}}$ is the concentration $(\mathrm{mg} / \mathrm{l})$ in the effluent; $Q$ is the inflow $\left(\mathrm{m}^{3} /\right.$ day); $S$ is the surface area of the wetland bed $\left(\mathrm{m}^{2}\right)$.
Statistical analyses were carried out using nonparametric tests, because a normal distribution could not be assumed after the one-sample Kolmogorov-Smirnov test. The nonparametric Kruskal-Wallis test was performed to determine differences in concentrations and removal efficiencies (concentration percentage abatement) among the 3 years of operation for each HSF-CW unit. Where the Kruskal-Wallis test showed significant differences between units, the Mann-Whitney $U$ test was used to evaluate pair comparisons. In addition, the comparison between HSF-CW units for each year of operation was also carried out. Statistical analyses were performed via The SPSS Statistics 23.0 (IBM, USA), and the differences were regarded as significant at $p<0.05$.

\section{Wetlands' electrical resistivity survey}

The vertical electrical survey was performed in this study to gain knowledge about the internal structure of the treatment wetlands (HSF-CW1, HSF-CW2), with the aim of detecting any operational anomalies commonly reported for reed beds such as clogging, lateral losses or short-circuited flow, and dead zones that ineluctably influence the wetlands' performance. Based on the lab-scale experiments conducted by Liu et al. (2018a), the feasibility of the resistivity method was further examined in the present work on full-scale HSF$\mathrm{CW}$ units for investigating the superficial depth properties of reed beds, especially for in situ detection of clogging. In this case study, we first explored the feasibility of the electric trail method in the field as a simple and suitable technique to monitoring wetlands, based on series of apparent electrical resistivity measurements for a rapid on-site survey. The apparent resistivity was measured by an AMNB quadrupole device, based on the Wenner arrays (Figure 1b) dealing with different spacings $(a)$ between the AMNB electrodes. The depth reached by the current lines is function of the spacing $(a)$ between the AMNB electrodes and the true resistivity of all materials present in the subsurface reed-bed; the greater the spacing $(a)$, the greater the depth of investigation $(P)$. Based on the Wenner device, the AMNB electrodes should be equidistant and evenly spaced ( $\mathrm{AM}=\mathrm{MN}=\mathrm{NB}=a=\mathrm{AB} / 3)$, i.e., $0.266,0.533,0.8,1.066$, and $1.333 \mathrm{~m}$, to investigate the reed beds, respectively, at $P$ 0.2-, 0.4-, 0.6-, 0.8-, and 1-m depths. The apparent resistivity is obtained as follows:

$\rho_{a}=2 \times \pi \times a \times \frac{\Delta V}{I}$

Reed bed survey was performed in September 2020 by a resistivity meter: PASI GEA RM1 type, to measure the apparent resistivity in subsurface reed beds $\left(\rho_{\mathrm{a}}\right)$, the intensity of the current $I$, and the potential difference $\Delta V$. According to the chosen mesh $(5 \mathrm{~m} \times 5 \mathrm{~m})$ as well as the geometry of each wetland unit, we performed for HSF-CW1 27 prospecting 


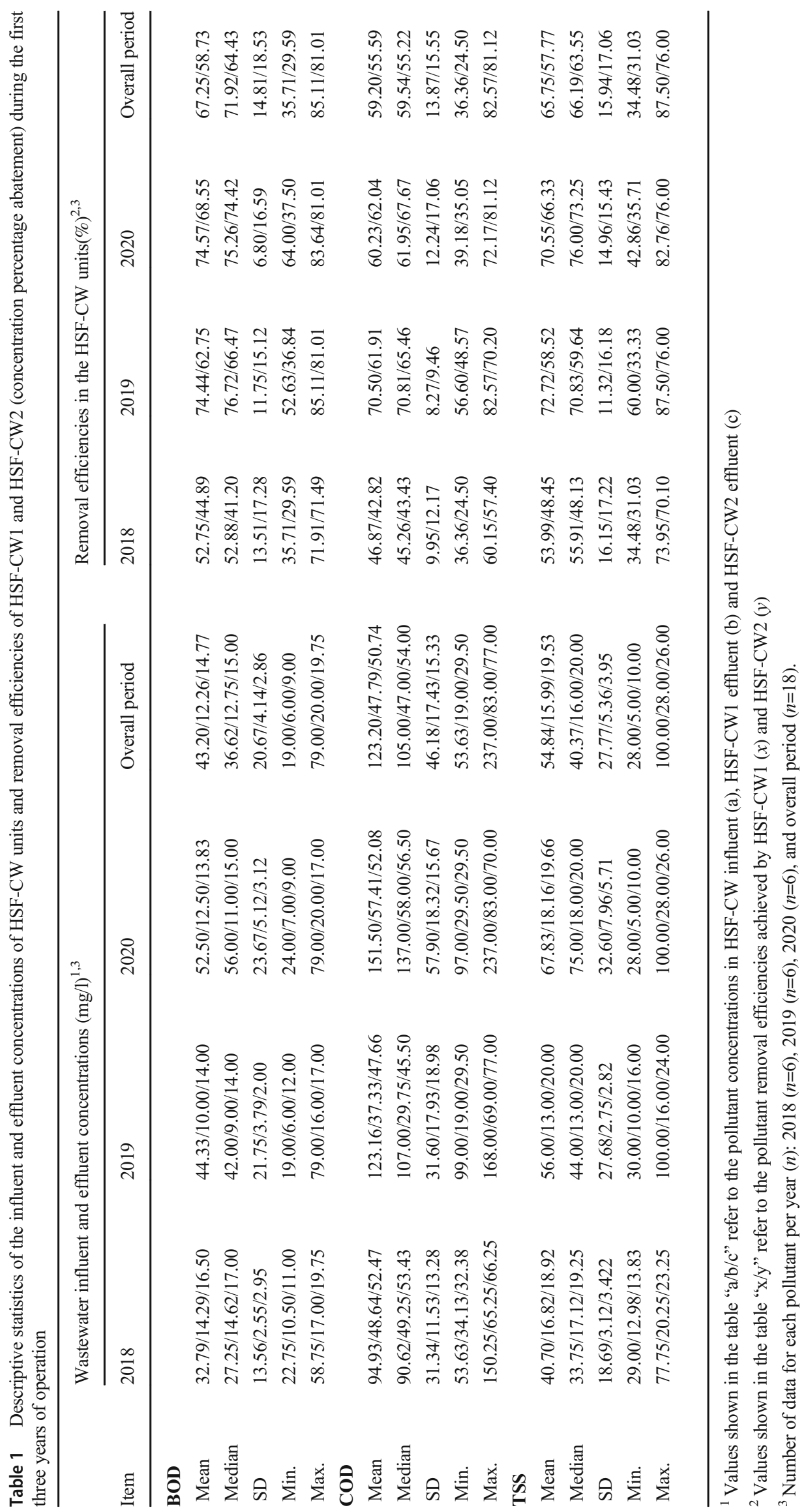


Fig. 2 Variation of influent and effluent concentrations and removal efficiencies at each HSF$\mathrm{CW}$ unit during the operation period for $\mathbf{a} \mathrm{BOD}, \mathbf{b} \mathrm{COD}$, and $\mathbf{c}$ TSS
HSF-CW inlet HSF-CW1 outlet HSF-CW2 outlet — HSF-CW1 REM\% — HSF-CW2 REM\%

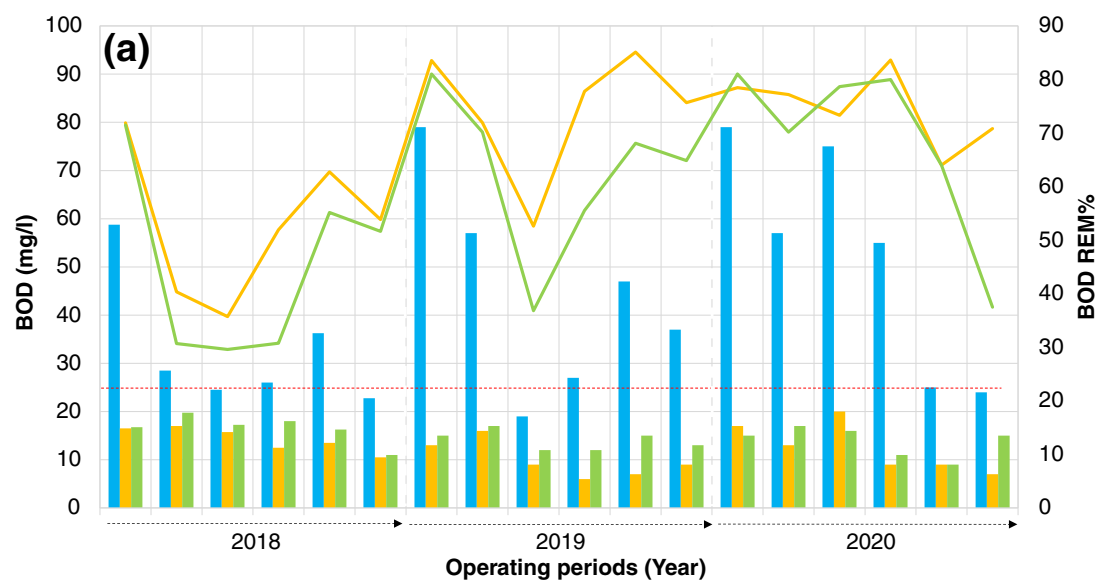

HSF-CW inlet HSF-CW1 outlet HSF-CW2 outlet - HSF-CW1 REM\% - HSF-CW2 REM\%

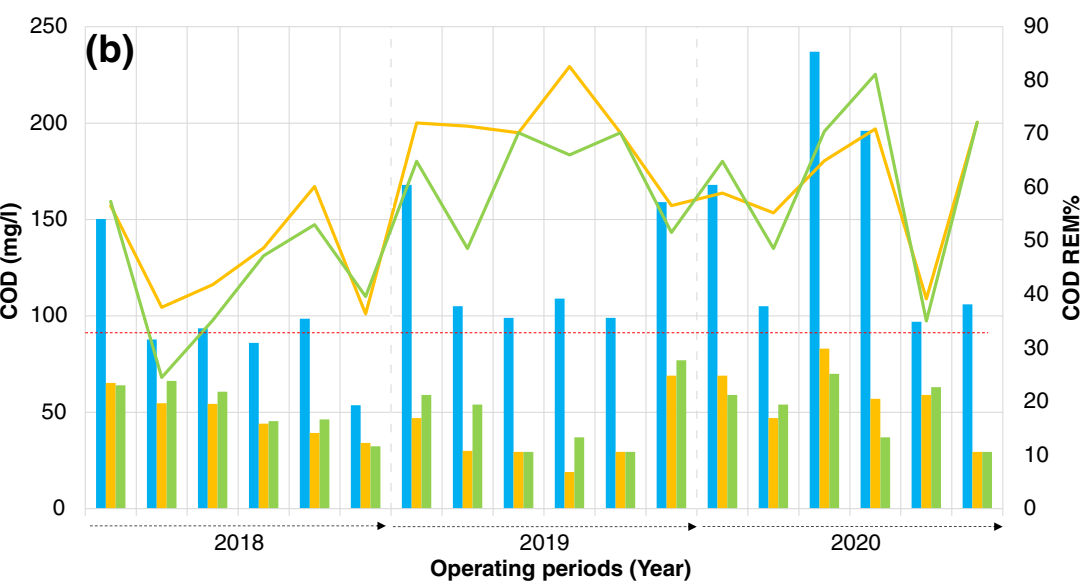

- HSF-CW inlet HSF-CW1 outlet HSF-CW2 outlet - HSF-CW1 REM\% - HSF-CW2 REM\% 120

(c)

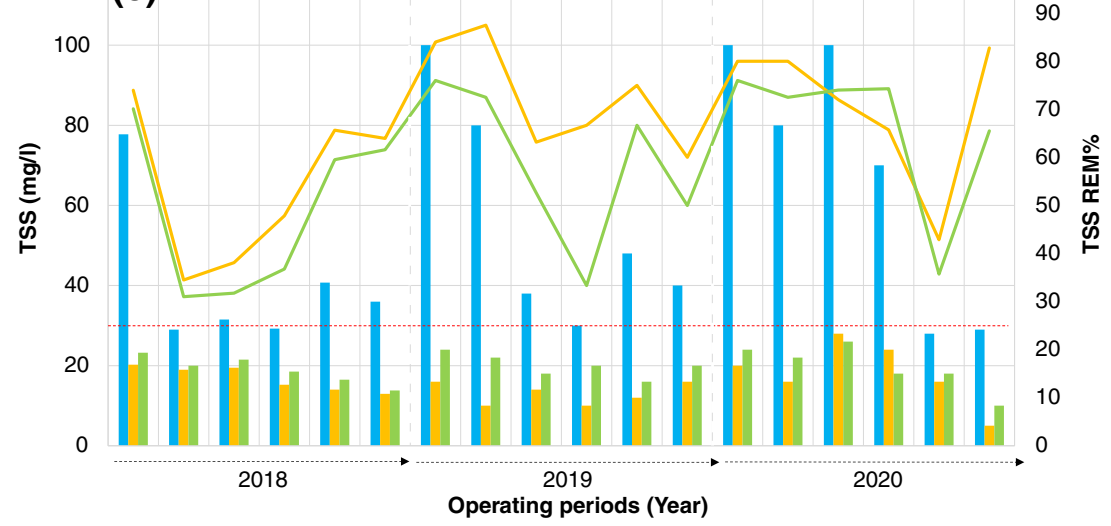

points over three lines, and 22 points for HSF-CW2 over two lines (Figure 1a). At each point, measurements are taken for 5 depths (Figure 1b). Overall, we carried out 47 prospecting points dealing with 235 measurements. This aims to achieve iso-resistivity mapping. The interpolation method chosen for data processing and map development is Kriging, facilitated by the ARCGIS (v 10.6) software.

\section{Results and discussion}

\section{Performance of the treatment wetlands}

In this case study, the full-scale HSF-CW units (two reed beds in parallel) were primarily designed to remove organics (BOD and COD) and TSS from reclaimed municipal wastewater for 
reuse application. The wetland was completed at the end of 2017 and water quality was monitored from the outset. Table 1 shows the mean values of BOD, COD, and TSS (and their standard deviations) in the influent and treated wastewater, as well as the removal efficiencies achieved by the HSF-CW units (HSF-CW1 and HSF-CW2). The dataset was organized according to the first 3 years of operation (2018, 2019, and 2020). Figure 2 presents the variation of the studied pollutants in the influent and effluent of HSF$\mathrm{CW}$ full-scale units throughout the entire study period, as well as the removal efficiencies of each pilot-scale unit.

Over the full monitoring period, the mean BOD, COD, and TSS concentration values in the influent to the treatment wetland were $43.20 \pm 20.67 \mathrm{mg} / 1,123.20 \pm 46.18 \mathrm{mg} / \mathrm{l}$, and $54.84 \pm$ $27.77 \mathrm{mg} / \mathrm{l}$, respectively. Regarding organics, the results show a satisfactory decrease in BOD and COD values with the average outflow concentrations well below the legal limits (Tunisian standards for irrigation uses) of $30 \mathrm{mg} \mathrm{O} / 1$ for BOD and $90 \mathrm{mg} \mathrm{O}_{2} / 1$ for COD. In addition, despite the great variability of influent quality (Figure 2a, b) as expressed by the standard deviation values of organics concentrations (Table 1), the HSF-CW units produced a comparable high quality of effluents that fit well agricultural needs, as well as satisfactory treatment efficiency since the start-up of wetlands' operation. During the overall operating period, the average concentration-based removal efficiencies achieved by HSF-CW1 and HSF-CW2 were BOD $67.25 \pm 14.81 \%$ and $58.73 \pm 18.53 \%$, and COD $59.20 \pm 13.87 \%$ and $55.59 \pm$ $15.55 \%$, respectively. For a similar operating period, García et al. (2005) reported comparable results, while higher performance is commonly reported for such long-term operated systems (Cooper 2009; Vymazal 2019).

Regarding the performance of each HSF-CW unit, the Kruskal-Wallis test indicated that the differences in percent removal of organics among the years of operation were significant $(p<0.05)$ for HSF-CW1 and HSF-CW2. The MannWhitney $U$ test was used to find between which years the differences were significant. For both HSF-CW units, the BOD removal in 2020 was statistically significantly higher than that in 2018 (Mann-Whitney $U$ test: $p<0.05$ ). Although both units showed an upward trend in performance during the second year of operation, no significant improvement was achieved later on. After the 3-year operation, comparable to BOD, the HSF-CW units showed an overall upward trend in COD removal between 2018 and 2020. However, while the performance of the reed beds improved significantly in 2019 compared to 2018 (Mann-Whitney $U$ test: $p<0.05$ ), a decreasing trend in COD removal was observed for HSF-CW1 between 2019 and 2020, in contrast to the performance of HSF-CW2 which remains almost steady.

Concerning suspended solids, the Kruskal-Wallis test indicated that the differences in removal efficiencies among the years of operation were not significant $(p>0.05)$ for both
HSF-CW units. However, the removal rates were more or less comparable to organic matter with an increasing trend over the years of operation (Table 1), which is likely due to effective retention of particles in the filtration beds, despite the strong variations in the influent water quality (Figure 2c). While the mean TSS outlet concentrations remain well below the legal limits of $30 \mathrm{mg} / \mathrm{l}$, such (high) variability in influent water quality could ultimately affect the subsequent filtration through the horizontal subsurface flow system, and therefore gradual clogging issues could inevitably arise when feeding the reed beds, mainly due to lack of pre-treatment. Although the aforementioned trends/differences are more or less important to date, some specific operating characteristics to HSF$\mathrm{CW}$ units and key design parameters reported in Table 2 could significantly affect the overall performance of the reed beds in the long term (Rahman et al. 2020).

Overall, when compared to HSF-CW2, HSF-CW1 achieved relatively higher performance throughout the monitoring study. Nevertheless, from the outset of the treatment process, it should be noted that the average hydraulic loading rate (HLR) applied to HSF-CW1 was up to $20 \%$ higher than HSF-CW2(Table 2), which could ultimately influence the pollutant removal efficiencies. However, this may only partially explain the mixed performances or the current trends/differences noticed between HSF-CW units in removing organics or solids. Regarding other key design parameters reported in Table 2 , the geometry of the wetlands for instance (i.e., the length to width ratio) was quite different in the HSF-CW units as originally designed with 3:1 for HSF-CW1 and 6:1 for HSF-CW2. According to Wu et al. (2015), the recommended aspect ratio should be less than 3:1. However, the effect of this factor on the efficiency of subsurface wetlands is not important in comparison with HLR (García et al. 2005). The latter is directly linked to the hydraulic retention time (HRT) which is an important factor as well as HLR, both affecting the treatment efficiency of the wetland system (Rousseau et al. 2008; Abou-Elela et al. 2013).

HRT is a very crucial factor in wetlands' design performance assessment, mainly in the settling of solids and biochemical processes (Almuktar et al. 2018). Considering the useful volume of wetlands' clean beds, the average nominal wetland detention time (HRT) was about 0.36 day for HSFCW1 and 0.47 day for HSF-CW2, as calculated based on the initial wetland design criteria and according to Kadlec and Wallace (2009), while the actual HRT was higher during the first 3 years of operation, with almost 0.52 day for HSF-CW1 and 0.67 day for HSF-CW2. In both situations, these values remain well below the recommended HRT of 2-5 days to achieve satisfactory wetland treatment performance, as recently reported by Almuktar et al. (2018) and Rahman et al. (2020). Otherwise, according to the same authors' recommendations dealing with HLR design criteria $(<0.5 \mathrm{~m} /$ day $)$, the average applied loads mostly to HSF-CW1 and HSF-CW2 being respectively 242 and $121 \mathrm{~m}^{3} /$ day (HLR, $0.36 \mathrm{~m} /$ day 
Table 2 Recommendations on the design and operation of subsurface flow constructed wetlands (SF-CW) for wastewater treatment (Adapted from Wu et al. 2015), and surface loading rates (SLR)(Adapted from Vymazal 2018, 2019)

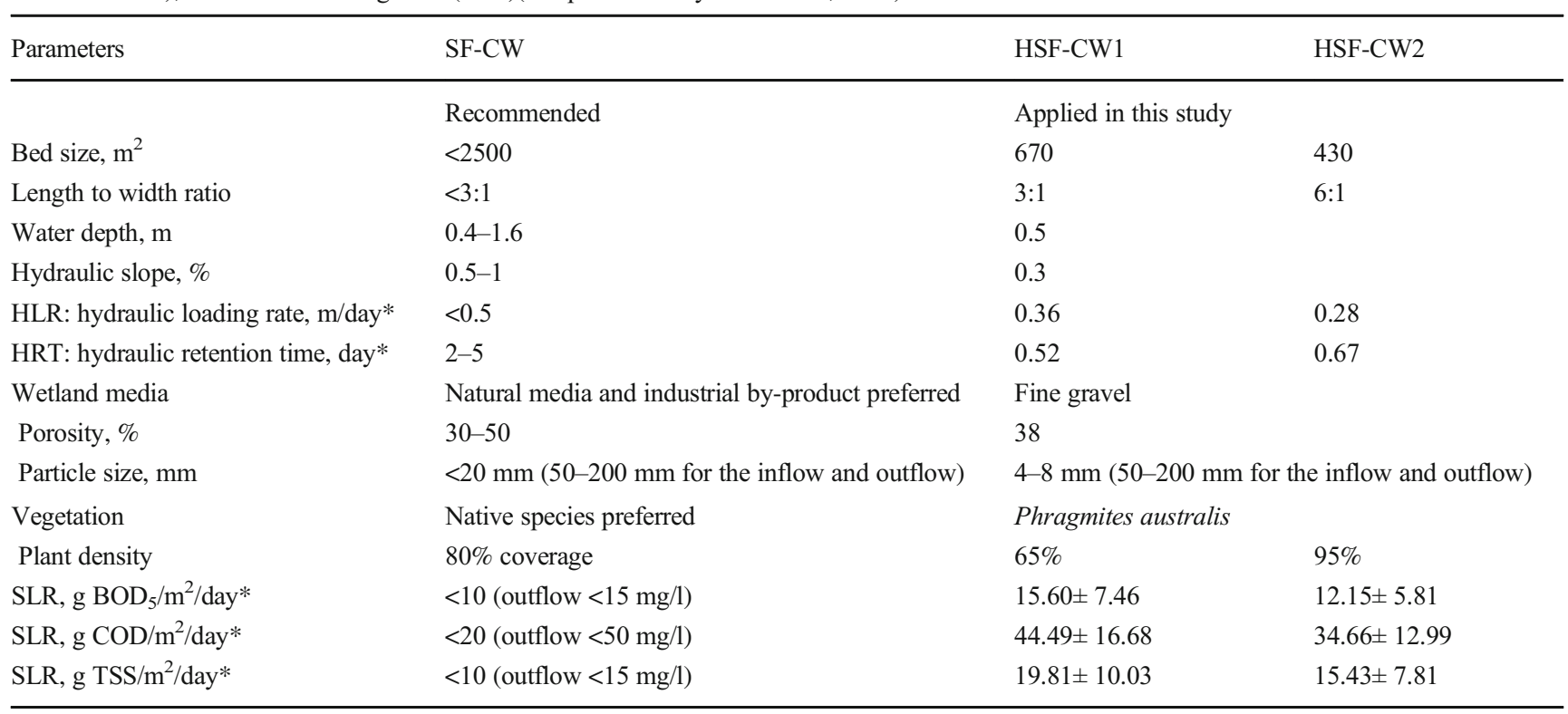

*Average estimated values over the first 3 years of operation

and $0.28 \mathrm{~m} /$ day) should be appropriate (Table 2). Nevertheless, for low hydraulic retention time, the organic matter in the reclaimed water will pass more or less quickly through the wetland substrate without adequate contact time for biodegradation processes resulting in low treatment performance. However, the removal of suspended solids is mainly a physical separation process than microbiological and as such is slightly affected by the retention time (Manios et al. 2003), although an extended HRT would promote better removal efficiency of particles (Panrare et al. 2015).

Anyway, in a recent comparative study conducted by Thalla et al. (2019), on subsurface constructed wetlands, significant removal rates of organics were obtained dealing with HRT of $0.5-1$ day close to those calculated under our local operating conditions. Yet higher solids removal has been reported. The hydraulic retention time is one of the few operational factors, which can be controlled in wetland systems by varying the influent flow rate when needed. However, the areal loading rate is difficult to control as the influent compositions vary significantly. Over the past 3 years of operation, the average loading rates applied to HSF-CW1 were calculated as $19.81 \pm 10.03,15.60 \pm 7.46$, and $44.49 \pm 16.68 \mathrm{~g} / \mathrm{m}^{2} /$ day for TSS, DBO, and COD, respectively (Table 2). Meanwhile, the rates applied to HSF-CW2 were $15.43 \pm 7.81,12.15 \pm 5.81$, and $34.66 \pm 12.99 \mathrm{~g} / \mathrm{m}^{2} /$ day for TSS, DBO, and COD, respectively. Although the rates applied to HSF-CW2 are relatively lower, HSF-CW1 was likely to be more efficient in removing solids and organics despite a lower hydraulic retention time.
In general, there is usually no design value for loading with TSS for horizontal subsurface flow systems. Over the past two decades, only US EPA guidelines recommend a loading $<20$ $\mathrm{g} / \mathrm{m}^{2} /$ day to achieve an outflow concentration of $30 \mathrm{mg} / \mathrm{l}$. In this context, the average TSS loads applied to the HSF-CW units were roughly acceptable over the first 3 years of operation, despite some variability in solids concentrations during the monitoring period (Table 1), even an overload if we consider the recent recommendations highlighted by Vymazal (2018, 2019)(Table 2). Besides, the organic load rates applied throughout the operation of the reed beds are quite high for both HSF-CW systems. These values are even higher than the limit of $16 \mathrm{~g} \mathrm{COD} / \mathrm{m}^{2} /$ day recommended by German guidelines or limits $1.6 \mathrm{~g} \mathrm{BOD} / \mathrm{m}^{2} /$ day (outflow $20 \mathrm{mg} / \mathrm{l}$ ) and $6.0 \mathrm{~g}$ $\mathrm{BOD} / \mathrm{m}^{2} /$ day (outflow $30 \mathrm{mg} / \mathrm{l}$ ) recommended by US EPA for horizontal subsurface treatment wetlands. While still achieving satisfactory performance, it is interesting to note here that during the first years of operation, probable early signs of clogging were noticed for both HSF-CW units, mainly dealing with both a partial ponding in the inflow zone and a subsequent partial overland flow with deposits on the surface of reed beds. While this has been more or less predictable in the long run, with solids loading rates at the top end of aforementioned recommended values, this should not compromise wetlands' performance, especially since a pre-treatment device is already planned to mitigate the applied loads.

According to Vymazal (2018), if the inflow loading rates are $<10 \mathrm{~g} \mathrm{BOD} / \mathrm{m}^{2} /$ day, $<20 \mathrm{~g} \mathrm{COD} / \mathrm{m}^{2} /$ day, $<<10 \mathrm{~g} \mathrm{TSS} /$ $\mathrm{m}^{2} /$ day, the partial ponding may occur after about 15 years of 
operation. Furthermore, the same author highlighted that if properly loaded, partial surface ponding of gravel-based horizontal subsurface flow constructed wetlands has no effect on treatment removal of solids and organics after 20 years of operation (Vymazal 2019). A study conducted by Vasconcellos et al. (2019) from start-up to heavy clogging of horizontal wetland systems (planted or unplanted) highlighted that the type of pre-treatment and the applied loads influenced more the performance of the units than the period of operation itself. Wang et al. (2021) recently reported that organic load is one of the most influencing factors of wetland clogging. The same authors mentioned that selection of aquatic plants with developed root should be recommended to reduce clogging problems.

It is worth noting that pollutant removal also depends on wetland vegetation. The latter has mostly a positive effect, i.e., supports higher treatment efficiency (Vymazal 2011). The comparison of the performance of vegetated subsurface flow wetlands and unplanted ones is not unanimous, yet most studies have shown that vegetated units outperformed unplanted units (Almuktar et al. 2018). The plants growing in constructed wetlands have several properties to the treatment process that make them an essential component of the design (Vymazal 2011). In general, a plant density of $80 \%$ cover as recommended by $\mathrm{Wu}$ et al. (2015) allows satisfactory treatment efficiency. Even if native species are also recommended, by far the most frequently used plant around the globe is Phragmites australis. The latter, however, has not always been the most effective species for use in phytoremediation, as reported by Milke et al. (2020). Both planted by common reeds, HSF-CW1 and HSF-CW2 have a plant density below and above $80 \%$ cover, respectively. During the last 3 years of system monitoring, HSF-CW2 showed a homogeneous distribution of vegetation while heterogeneous for HSF-CW1, especially towards the wastewater outlet area. Since the commissioning of the post-treatment plant, the two reed beds operating in parallel have shown comparable organics removal rates, except a drop in BOD removal efficiency for HSFCW2. Overall, organics removal efficiency of HSF-CW1 was relatively higher than that of HSF-CW2.

The role of vegetation in horizontal flow wetlands is mainly linked to physical processes such as providing increased surface area for attached microbial growth, and for providing better filtration of total suspended solids (TSS). Over the full monitoring period, the average concentration-based removal efficiencies of TSS for HSF-CW1 and HSF-CW2 were 65.75 $\pm 15.94 \%$ and $57.77 \pm 17.06 \%$, respectively. Although the removal of TSS for the two wetland units has been relatively comparable since starting operation and dealing with satisfactory output concentrations $(<30 \mathrm{mg} / \mathrm{l})$, a steady increasing trend in performance have been noticed, in particular for HSF-CW2. The latter exhibited better density of wetland vegetation during the whole monitoring period, yet performance is relatively lower. Vymazal (2011) reported that plants have usually no effect on removal of suspended solids indicating that retention of such pollutant is mainly through abiotic processes.

However, the effects of both solids accumulation and plant root can result in hydraulic malfunction and reduced service life, mainly dealing with clogging issues (Liu et al. 2018b). Hydrodynamics of HSF-CW systems have been studied by many researchers (Licciardello et al. 2019, 2020), and internal hydraulic features specific to each HSF-CW unit such as preferential flow in the bottom layer of reed beds (Garcia et al. 2003) may explain in part overall performance. It should be noted that the predominant physical mechanisms for suspended solids removal are generally flocculation/ sedimentation and filtration (Kadlec 2009). The most significant component of these systems is the substrate material filtering the wastewater. The material both provides a medium for rooting of aquatic plants and distributes influent, directs and collects effluent, provides surface area for microbial activity, and filters suspended solids. In general, it is admitted that the roots of macrophytes and porous media in this system are responsible for biomass development and subsequently enhance pollutants removal (Almuktar et al. 2018).

A review on the sustainability of constructed wetlands for wastewater treatment recommended the use of natural media and industrial by-product with preferred media porosity 0.3 0.5 and particle size $<20 \mathrm{~mm}$ (Wu et al. 2015). Horizontal flow gravel beds are commonly used in many countries for secondary and tertiary treatment of domestic wastewater with a gravel size typically between 4 and $20 \mathrm{~mm}$ (IWA Task Group 2017). The preliminary results of the present study indicate that the use of fine gravel $(4-8 \mathrm{~mm})$ as a porous medium allowed a satisfactory HSF-CW performance in relation with the local effluent standards, despite the variability already mentioned above in the influent quality. Similar results for relatively comparable gravel sizes have been reported by García et al. (2005) and Cooper (2009). Overall, despite the influent water quality variations, the mixed pattern of removal efficiencies achieved by HSF-CW units over time could be attributed to possible filtration-bed clogging or rather differences in the extent and subsequent effects of substrate clogging.

\section{Detection of operating anomalies (clogging)}

Rousseau et al. (2008) reported that clogging is a tangible risk in subsurface flow systems and is primarily influenced by loading rates of organics and/or solids, the HLR, the particle size, and distribution of the matrix material as well as the particle content of wastewater. Water pretreatment is also very important to prevent the rapid clogging of the filtration bed. In the full-scale HSF-CW system, the excessive loads applied since start-up operation as well as the variability in the quality 
of the reclaimed water would support the hypothesis of an earlier clogging of the wetland units. Besides, the first signs of clogging were suspected at the end of the first year of operation as surface ponding events firstly occurred intermittently in the inflow zone of both wetland units dealing with a partial overland flow, which has become quite common over time. It is worth noting that one of the main weaknesses of the initial HSF-CW design is the lack of a pre-treatment device, which should accelerate clogging processes when feeding HSF-CW units. In either case, this would not allow the wetland beds to operate within the range of its intended design and may result in earlier severe clogging.

Since start-up, wetland operation was more or less regular, and it should nevertheless be emphasized the COVID-19 drastic impacts on the treatment plant, in particular the very irregular operation of wetlands as well as the lack of maintenance in 2020. The current status of the full-scale treatment wetlands is challenged with the urgency to provide a rapid/ meaningfulon-site diagnosis and factual data to convince decision-makers to support innovation and make improvements to this pilot/full-scale system (the way ahead), especially since the treatment plant is currently co-managed by local civil society (GDA Sidi Amor) and the national sanitation utility (ONAS). Although the establishment of a pre-treatment system (settling tank upstream of HSF-CW) is already planned, it is important to detect and delineate the presence of the subsurface anomalies of HSF-CW in order to sustain the management of the whole system. To do so, the vertical electrical survey (VES) was tested in this study to gain knowledge about the internal structure of the two HSF-CW units (HSF-CW1, HSF-CW2) in order to evaluate the potential of clogging for reed beds and to detect potential failures of the system such as lateral losses or short-circuited flow and dead zones.

The geo-electrical technique used here for investigation is that of electric trails, based on series of apparent electrical resistance measurements, in order to study superficial depth properties of the subsurface flow treatment wetlands. The resistivity distribution of the subsurface flow zone is influenced by many parameters such as the nature and structure of the solid fraction, the water content, and the liquid-phase electrical conductivity (Liu et al. 2018a). In the electrical resistivity method, multiple measurements of the medium transfer resistance using a four-electrode array allow to reconstruct the resistivity distribution of subsurface wetland beds (Binley and Kemna 2005). The transfer resistance is the ratio between the potential measured between two electrodes $(\mathrm{M}$ and $\mathrm{N})$ and the current injected between the two others (A and B). Multiplying the number of measurements and varying the spacing of electrodes allow investigating the participation of different bed volumes to the measured resistivity (Forquet and French 2012; Marzo et al. 2018; Garcia-Artigas et al. 2020).

In this study, VES measurements according to Wenner arrays were used to identify horizontal and vertical variability of the wetlands' flow distribution over the examined profiles. The Wenner method is suitable for horizontal subsurface wetlands rather than vertical one by providing a good resolution of shallow ground. The principle is different from that of electrical sounding, and consists in performing a series of measurements with the same device (same spacing between electrodes) by moving the latter along a selected axis, i.e., the experimental setup is moved along the surface of the wetland bed while the measurement is made. In this study, electrical resistivity surveys were performed in September 2020 through 47 prospecting points: 27 for HSF-CW1 and 22 for HSF-CW2 carried out over three and two lines respectively, and each point corresponding to 5 depths, i.e., a total of 235 measurements. Figure 3 shows the distribution of electrical resistivity (ER, $\Omega \cdot \mathrm{m}$ ) at different depths of reed beds (HSF-CW units) down to $0.6 \mathrm{~m}$, as well as the underlying layers down to $1 \mathrm{~m}$, i.e., below geosynthetic liner.

Figure 3 a shows the ER slices (horizontal profiles) acquired from top to bottom of the HSF-CW1 bed substrate (till 0.6-m depth). The general pattern of ER distribution exhibits a non-symmetrical horizontal distribution of resistivity as well as vertical variability. An overall analysis of all profiles would first be favorable to the hypothesis of likely layered cloginduced preferential flow pathways, which should be a relatively common phenomenon in the situation of severe clogging of HSF-CW systems as described in lab-scale experiments by Liu et al. (2018a, 2018b), in particular through the left side (compartments A and C) towards the outlet device, as assumed from the extreme and intermediate values of the apparent resistivity of the wetland substrate. Some ER anomalies dealing with high ER values occurred in the inlet zone (SW, compartment $\mathrm{D}$ ) and all along the right side of the wetland bed towards the exit area (compartment E) as well as the left boundary (NE, compartment C). According to field observations (visual monitoring) carried out during the last years of reed bed operation, partial ponding in the inflow zone of HSF$\mathrm{CW} 1$ and surface runoff with subsequent deposits on the wetlands surface often first occurred in compartment A towards the outlet zone by crossing compartment C. Both compartments show anomalies dealing with the lowest ER values, while compartments $\mathrm{B}, \mathrm{D}$, and $\mathrm{E}$ have the lowest density of vegetation. Samsó and García (2014) have previously drawn attention to the fact that the clogging process begins next to the inlet end and progresses down the length of the bed over the years. In addition, Liu et al. (2018a) and Marzo et al. (2018) showed that clogged areas in reed beds had the lowest values of resistivity and vegetation density, respectively.

In this study, an ER anomaly zone (prospecting point 1-17) with the lowest values $(11.53$ and $15.95 \Omega \cdot \mathrm{m}$, respectively at 0.2- and 0.4-m depths) occurred a few meters from the inlet zone and further in the same direction towards the outlet zone specifically to the $0.6-\mathrm{m}$ slice (prospecting point 1-13: 25.23 $\Omega \cdot \mathrm{m})$. This may be attributed to possible clogged zone or 
a
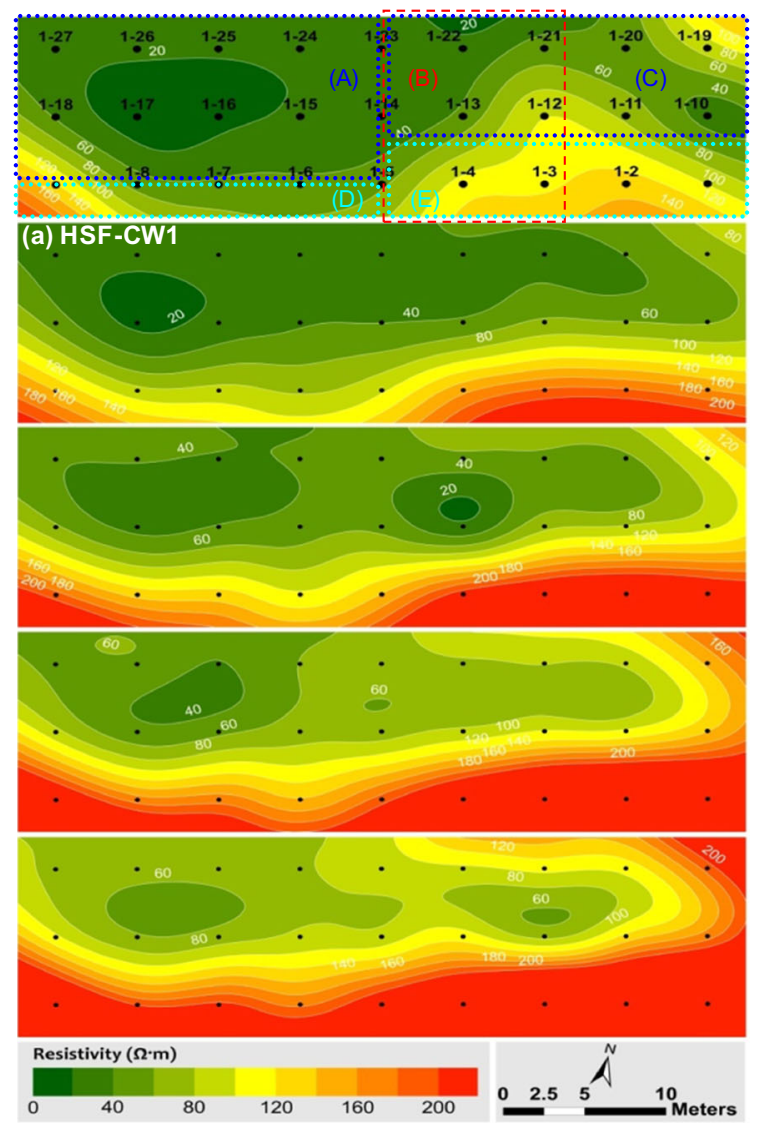

Fig. 3 Iso-resistivity depth slices from top to bottom reed beds (depths of $0.2,0.4$, and $0.6 \mathrm{~m})$, and below geosynthetic liner $(0.8$ and $1.0 \mathrm{~m})$ based on the prospecting points in a HSF-CW1, and bHSF-CW2;

rather a favorable area to clogging material accumulation, with likely the existence of a preferential flow which would have increased the solid loading in the bottom section of the wetland. Comparable findings by Liu et al. (2018b) showed that with the traditional design of HSF-CW systems, it was easy to develop the preferential bottom flow, and most of the clog matter was accumulated near the inlet zone. In general, clogging is dominated by biological solids when treating wastewater with a high organic load. Biological solids could facilitate the occurrence of low-density gelatinous clog matter with high water retention capacity (Knowles et al. 2011). The accumulation of these solids could also reduce the apparent resistivity of the substrate. Besides, the electrical resistivity could be a significant marker of (biological) solids fraction as described in recent studies (Liu et al. 2018a). Anyway, in this study, similar trends in the distribution of ER are curiously noted with the deeper layers, i.e., beyond the geosynthetic liner, and thus suggesting a possible migration and accumulation of fine solids through the percolation of wastewater into the subsoil.

Based on both overall iso-resistivity profiles (Figure 3a) and field observations, prospecting points 1-16/1-17 and the

$\mathrm{b}$
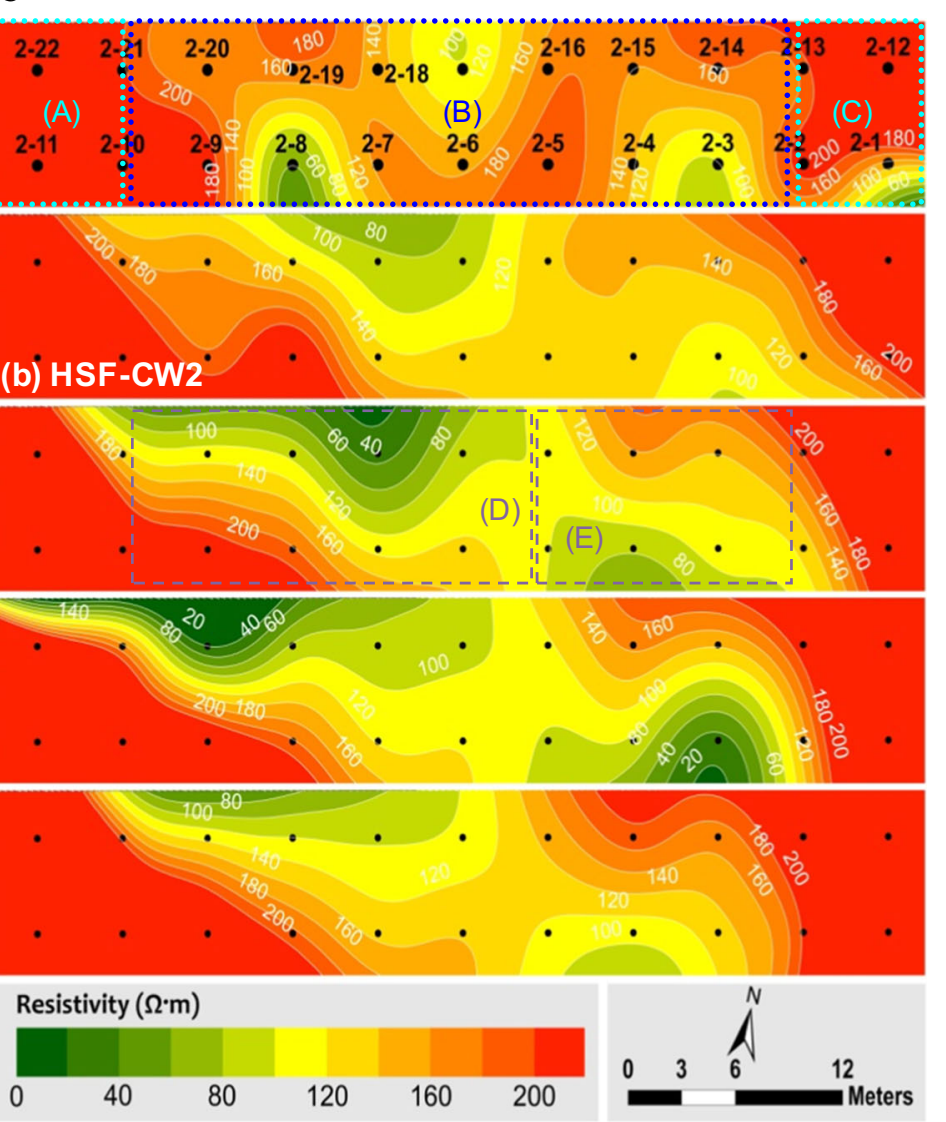

compartments A, B, C, D and E indicate areas of homogeneity and/or heterogeneity of apparent resistivity with extreme ER values

surrounding areas are clearly marked respectively by a low apparent resistivity and a high vegetation density, which extends roughly over the entire inlet filtration zone to the middle of the filter bed, but mainly to the left side. This likely suggests deterioration of the geosynthetic liner in this area as well as a more conductive (clogged) zone, yet reeds density is particularly quite high in this area. Marzo et al. (2018) reported comparable findings, supporting deposition of organic matter and settleable solids to clogged zones, yet lower vegetation density was observed in the same zone. Thus, compartment B is suspected to present severe clogging. Anyway, when moving to the second half of the reed bed towards the outlet zone, in situ observations indicated for prospecting point 1-13 and the surrounding area (compartment B) lower vegetation density and heterogeneous/poor development up to the outlet of the wetland bed, especially to the right side (compartment E). It should be noted here that since the start-up of the treatment plant, this filter area (E) was suspected of being a dead zone as the growth and density of the vegetation were but still low. Clearly, by relying on the influence of the localized drainage system (nozzle) located at the opposite boundary (NE, compartment C), but also on the presumed clogged area upstream, 
as well as the inferred clog-induced preferential flow pathways through the left side of the wetland bed, could explain the presence of this dead zone. Hydraulic behavior, and therefore water flow paths, was likely greatly influenced by the outlet device position, as already pointed out by Pedescoll et al. (2013).

Figure $3 \mathrm{~b}$ shows the ER slices (horizontal profiles) acquired from top to bottom of the HSF-CW2 bed substrate, i.e., till 0.6$\mathrm{m}$ depth, and below the liner down to $1 \mathrm{~m}$. Compared to HSFCW1, the ER distribution also exhibits a heterogeneous horizontal distribution of resistivity as well as vertical variability, yet the ERs acquired in the filling or draining areas (compartment $\mathrm{A}$ and $\mathrm{C}$ ) are relatively homogeneous and show the highest values. The intermediate filtration zone (compartment B) from the inlet to the outlet of HSF-CW2 has the lowest ER values overall, with low ERs specifically to the $0.2-\mathrm{m}$ slice in compartment $\mathrm{C}$ (SE). The latter may be compared to similar draining area identified in HSF-CW1 as close ERs are observed at the extreme limit of the outlet bed (NE, compartment C). Since the drain pipe connector is located therein, this might be explained very likely by fine solids accumulation over time dealing with preferential water flow paths, as already mentioned above for HSF-CW1.

More focused on compartment B, the 0.2-m slice shows an uneven and dispersed distribution of ERs dealing with some anomalies (low ERs) located approximately around prospecting points 2-3, 2-8, and 2-17, suggesting the presence of clogged zones. In fact, in situ observations indicated deposition of organic matter, settleable solids, and high vegetation density in these areas. In general, the presence of plant root restricted the water flow in the upper layer, and thus promotes the preferential bottom flow phenomenon. Besides, in the underlying layers (till 0.6-m depth), ERs show more or less extended homogenous distribution (compartments D and E) with a downward trend, supporting deposition of organic matter and settleable solids to clogged zones (Moreira et al. 2014), as well as likely preferential flow in the bottom layer of the reed bed (Garcia et al. 2003). On the other hand, the extent of solids accumulation in the upper layer (compartment B) could account the role of solid interception by the plant root near the inlet (compartment A). Typically, clogging occurs first in the inlet area, and it is commonly believed that this is the primary factor affecting flow pathways. Besides, Liu et al. (2018b) reported that the traditional design of HSF-CW was easy to develop the preferential bottom flow, and the solids accumulation near inlet zone promoted the fast bottom flow throughout the whole system. However, in the present work, it should be noted that frequent blocking of the perforated inlet pipe located upstream (along the width of a gabion area) probably did not allow a uniform distribution of wastewater across the inlet zone, while promoting both surface overland flow in the inlet zone and the upper layer flow. As shown in Figure 3 b, this likely implied the existence of a preferential flow that increased the solid loading in the bottom section of the influent end of compartment A (NE).

It should be noted that more or less rapid water level losses in the two reed beds were recently reported by the manager of the treatment plant regardless of the operating periods, and therefore the lateral losses linked to any possible degradation of the liner must be taken into account. The possible impermeability defects of the base of the HSF-CW systems related to cracks or other structural defects in the liner have already been reported by Casas et al. (2012) using geophysical investigation methods. For instance, if we focus more on prospecting points $2-14$ and $2-18$, the resistivity profiles acquired down to the bottom of the wetland substrate $(0.6-\mathrm{m}$ depth) present a net vertical decrease in the ER values for 218 and the area all around, unlike 2-14, assuming an accumulation of more conductive clogging materials and likely critical disparities in the degree of liner degradation. Thus, this assumes a possible perforation of the geosynthetic material at or around this location which should lead to the loss of wastewater through the liner with gradual migration and accumulation of fine solids to the subsoil. Anyway, the low ER values acquired under the geosynthetic liner probably testify to an early damping of the latter, which should be valid for both wetland units.

It should be noted that for both wetland units, the gravel filtration media was almost unwashed during the early stages of setting up the treatment plant; this can lead to clogging as unwashed media can contain high content fines (De Matos et al. 2018). From in situ observations, sharp edges are also noticed which can damage the liner and provide less ideal pore spaces, thus affecting porosity and subsequently the wetlands performances (Wang et al. 2021). Notwithstanding, the filtration beds filled with fine gravel $(4-8 \mathrm{~mm})$ still perform satisfactory pollutant removal rates after 3 years of operation, testifying to the robustness of the system despite mitigated operating conditions. However, major operational problems such as clogging of the substrate, in whole or in part, could lead to an inevitable decrease in purification capacity of constructed wetlands in the long term (Knowles et al. 2011; Vasconcellos et al. 2019). Thus, optimized methods in designs (e.g., pretreatment process) and operations (e.g., reduced loading) must be considered to mitigate the clogging progress (Nivala et al. 2012; Pedescoll et al. 2011, 2012). In addition, these measures could be more effective in mitigating the progress of clogging through optimized monitoring methods (e.g., electrical resistivity surveys) (Liu et al. 2018a).

\section{Conclusions}

This case study examined both the performance of long-term operated reed beds (two parallel HSF-CW units) as tertiary wastewater treatment, and the feasibility of the electrical 
resistivity (ER) method for in situ monitoring and detection of common operating anomalies such as clogging. Monitoring wastewater quality showed satisfactory treatment performance after 3 years of operation, despite high variability in the influent water quality and excessive applied loads of solids/organics. However, based on the ER survey and field observations, early signs of process failure, mainly related to clogging and likely lateral losses or dead zones, were noted. Besides, the ER survey strongly sustains the hypothesis of a presumed deterioration of the system's hydraulics due to clogging that came first than the deterioration of the effluent quality. Yet, caution should be paid to these preliminary, although promising, results as further investigation in the future is needed both to upgrade and to explore the use of the resistivity method for the detection (quantification) of clogging in the field and the characterization of clogging materials in subsurface reed beds. The current resistivity results would be foremost useful to the managers of HSF-CW systems, both to explore and then correct any suspected operational failures (detected) and to guide or rather prioritize the improvement actions to be undertaken in the short range.

Acknowledgements The study presented here was carried out within the framework of a pilot project funded by the World Bank to promote wastewater reclamation and reuse for agricultural irrigation in Tunisia. The authors wish to acknowledge the support of the National Sanitation Utility (ONAS) and the Agricultural Development Group of Sidi Amor (GDA Sidi Amor).

\section{Declarations}

Conflict of interest The authors declare that they have no competing interests.

\section{References}

Abou-Elela SI, Golinielli G, Abou-Taleb EM, Hellal MS (2013) Municipal wastewater treatment in horizontal and vertical flows constructed wetlands. Ecol Eng 61:460-468. https://doi.org/10. 1016/j.ecoleng.2013.10.010

Aiello R, Bagarello V, Barbagallo S, Iovino M, Marzo A, Toscano A (2016) Evaluation of clogging in full-scale subsurface flow constructed wetlands. Ecol Eng 95:505-513. https://doi.org/10.1016/j. ecoleng.2016.06.113

Almuktar SAAAN, Abed SN, Scholz M (2018) Wetlands for wastewater treatment and subsequent recycling of treated effluent: a review. Environ Sci Pollut Res 25:23595-23623. https://doi.org/10.1007/ s11356-018-2629-3

APHA/AWWA/WEF (2005) In: Eaton AD, Clesceri LS, Rice EW, Greenberg AE (eds) Standard methods for the examination of water and wastewater, 21st edn. American Public Health Association/ American Water Works Association/Water Environment Federation, Washington, DC

Binley AM, Kemna A (2005) DC resistivity and induced polarization methods. In: Rubin Y, Hubbard SS (eds) Hydrogeophysics. Water Sci. Technol. Lib. 50. Springer, New York, pp 129-156
Brix H (1987) Treatment of wastewater in the rhizosphere of wetland plants - the root zone method. Water Sci Technol 19:107-118. https://doi.org/10.2166/wst.1987.0193

Casas A, Tapias JC, Himi M, Lovera R, Blasco R, Folch M (2012) Application of electrical resistivity tomography technique for investigating subsurface flow constructed wetlands. Near Surface Geoscience 2012 - 18th European Meeting of Environmental and Engineering Geophysics. https://doi.org/10.3997/2214-4609. 20143399

Cooper P (2009) What can we learn from old wetlands? Lessons that have been learned and some that may have been forgotten over the past 20 years. Desalination 246:11-26. https://doi.org/10.1016/j.desal.2008. 03.040

De Matos MP, von Sperling M, de Matos AT (2018) Clogging in horizontal subsurface flow constructed wetlands: influencing factors, research methods and remediation techniques. Rev Environ Sci Biotechnol 17:87-107. https://doi.org/10.1007/s11157-018-9458-1

De Paoli AC, von Sperling M (2013) Evaluation of clogging in planted and unplanted horizontal subsurface flow constructed wetlands: solids accumulation and hydraulic conductivity reduction. Water Sci Technol 67:1345-1352. https://doi.org/10.2166/wst.2013.008

Ergaieg K, Ben Miled T (2021)Full-scale hybrid constructed wetlands monitoring for decentralized tertiary treatment of municipal wastewater. Arab J Geosci 14:1407. https://doi.org/10.1007/s12517-02107776-y

Forquet N, French HK (2012) Application of 2D surface ERT to on-site wastewater treatment survey. J Appl Geophy 80:144-150. https:// doi.org/10.1016/j.jappgeo.2012.02.002

Garcia J, Ojeda E, Sales E, Chico F, Piriz T, Aguirre P et al (2003) Spatial variations of temperature, redox potential, and contaminants in horizontal flow reed beds. Ecol Eng 21:129-142. https://doi.org/10. 1016/j.ecoleng.2003.10.001

García J, Aguirre P, Barragán J, Mujeriego R, Matamoros V, Bayona JM (2005) Effect of key design parameters on the efficiency of horizontal subsurface flow constructed wetlands. Ecol Eng 25:405-418. https://doi.org/10.1016/j.ecoleng.2005.06.010

Garcia-Artigas R, Himi M, Revil A, Urruela A, Lovera R, Sendrós A, Casas A, Rivero L (2020)Time-domain induced polarization as a tool to image clogging in treatment wetlands. Sci Total Environ 724:138189. https://doi.org/10.1016/j.scitotenv.2020.138189

Ghimire U, Nandimandalam H, Martinez-Guerra E, Gude VG (2019) Wetlands for wastewater treatment. Water Environ Res 91:13781389. https://doi.org/10.1002/wer.1232

Ghrabi A, Bousselmi L, Masi F, Regelsberger M (2011) Constructed wetland as a low cost and sustainable solution for wastewater treatment adapted to rural settlements: the Chorfech wastewater treatment pilot plant. Water Sci Technol 63(12):3006-3012. https://doi. org/10.2166/wst.2011.563

Greggio N, Giambastiani B, Balugani E (2018)High-resolution electrical resistivity tomography (ERT) to characterize the spatial extension of freshwater lenses in a salinized coastal aquifer. Water 10:1067. https://doi.org/10.3390/w10081067

Herrera-Melián JA, Mendoza-Aguiar M, Guedes-Alonso R, GarcíaJiménez P, Carrasco-Acosta M, Ranieri E (2020) Multistage horizontal subsurface flow vs. hybrid constructed wetlands for the treatment of raw urban wastewater. Sustainability 12(12):5102. https:// doi.org/10.3390/su12125102

IWA Task Group (2017) (Dotro G, Langergraber G, Molle P, Nivala J, Puigagut J, Stein O, Von Sperling M). Treatment wetlands. Volume 7. Biological Wastewater Treatment Series. IWA Task Group on Mainstreaming the Use of Treatment Wetlands. IWA Publishing, London. $154 \mathrm{p}$

Kadlec RH (2009) Comparison of free water and horizontal subsurface treatment wetlands. Ecol Eng 35(2):159-174. https://doi.org/10. 1016/j.ecoleng.2008.04.008 
Kadlec RH, Knight RL (1996) Treatment wetlands Lewis. Publishers/ CRC Press, Inc., Boca Raton

Kadlec RH, Wallace RD (2009) Treatment wetlands, 2nd edn. CRC Press, Florida 1016:435

Keffala C, Ghrabi A (2005) Nitrogen and bacterial removal in constructed wetlands treating domestic waste water. Desalination 185(1-3): 383-389. https://doi.org/10.1016/j.desal.2005.04.045

Khouja I, M'Hiri F, Ouzari HI, Saidi N (2019) Removal processes of indicator organisms and opportunistic pathogens in an anaerobic digester constructed wetland system. Water Environ J 34:342-354. https://doi.org/10.1111/wej.1253

Knowles PR, Griffin P, Davies PA (2010) Complementary methods to investigate the development of clogging within a horizontal subsurface flow tertiary treatment wetland. Water Res 44:320-330. https://doi.org/10.1016/j.watres.2009.09.028

Knowles P, Dotro G, Nivala J, García J (2011) Clogging in subsurfaceflow treatment wetlands: occurrence and contributing factors. Ecol Eng 37:99-112. https://doi.org/10.1016/j.ecoleng.2010.08.005

Licciardello F, Aiello R, Alagna V, Iovino M, Ventura D, Cirelli GL (2019) Assessment of clogging in constructed wetlands by saturated hydraulic conductivity measurements. Water Sci Technol 79:314322. https://doi.org/10.2166/wst.2019.045

Licciardello F, Sacco A, Barbagallo S, Ventura D, Cirelli GL (2020) Evaluation of different methods to assess the hydraulic behavior in horizontal treatment wetlands. Water 12:2286. https://doi.org/10. $3390 /$ w 12082286

Liu H, Hu Z, Song S, Zhang J, Nie L, Hu H, Li F, Liu Z (2018a) Quantitative detection of clogging in horizontal subsurface flow constructed wetland using the resistivity method. Water 10:1334. https://doi.org/10.3390/w10101334

Liu H, Hu Z, Zhang J, Ji M, Zhuang L, Nie L, Liu Z (2018b) Effects of solids accumulation and plant root on water flow characteristics in horizontal subsurface flow constructed wetland. Ecol Eng 120:481486. https://doi.org/10.1016/j.ecoleng.2018.07.003

Manios T, Stentiford EI, Millner P (2003) Removal of total suspended solids from wastewater in constructed horizontal flow subsurface wetlands. J Environ Sci Heal A 36:1073-1085. https://doi.org/10. 1081/ESE-120019865

Marzo A, Ventura D, Cirelli GL, Aiello R, Vanella D, Rapisarda R, Barbagallo S, Consoli S (2018) Hydraulic reliability of a horizontal wetland for wastewater treatment in Sicily. Sci Total Environ 636: 94-106. https://doi.org/10.1016/j.scitotenv.2018.04.228

Milke J, Gałczyńska M, Wróbel J (2020) The importance of biological and ecological properties of Phragmites australis (Cav.) Trin. Ex Steud., in phytoremendiation of aquatic ecosystems - the review. Water 12(6):1770. https://doi.org/10.3390/w12061770

Miranda ST, Matos AT, Matos MP, Borges AC, Baptestini GCF (2017) Characterization of clogging material from horizontal subsurface flow constructed wetland systems. Engenharia Agricola 37:463470. https://doi.org/10.1590/1809-4430-eng.agric.v37n3p463-470/ 2017

Moreira C, Castro M, Gonsalez A, Cavallari F, Munhoz T, Pereira A (2014) Comparative analysis between biogas flow in landfill and electrical resistivity tomography in Rio Claro city Brazil. J Geology Res 2014:1-7. https://doi.org/10.1155/2014/845906

Nivala J, Knowles P, Dotro G, Garcia J, Wallace S (2012) Clogging in subsurface-flow treatment wetlands: measurement, modeling and management. Water Res 46:1625-1640. https://doi.org/10.1016/j. watres.2011.12.051

Panrare A, Sohsalam P, Tondee T (2015) Constructed wetland for sewage treatment and thermal transfer reduction. Energy Procedia 79:567575. https://doi.org/10.1016/j.egypro.2015.11.535
Pedescoll A, Corzo A, Alvarez E, Garcia J, Puigagut J (2011) The effect of primary treatment and flow regime on clogging development in horizontal subsurface flow constructed wetlands: an experimental evaluation. Water Res 45:3579-3589. https://doi.org/10.1016/j. watres.2011.03.049

Pedescoll A, Knowles PR, Davis P, Garcia J, Puigagut J (2012) A Comparison of in situ constant and falling head permeameter tests to assess the distribution of clogging within horizontal subsurface flow constructed wetlands. Water Air Soil Pollut 223:2263-2275. https://doi.org/10.1007/s11270-011-1021-4

Pedescoll A, Sidrach-Cardona R, Sánchez JC, Carretero J, Garfi M, Bécares E (2013) Design configurations affecting flow pattern and solids accumulation in horizontal free water and subsurface flow constructed wetlands. Water Res 47:1448-1458. https://doi.org/10. 1016/j.watres.2012.12.010

Rahman ME, Bin Halmi MIE, Bin Abd Samad MY, Uddin MK, Mahmud K, Abd Shukor MY, Sheikh Abdullah SR, Shamsuzzaman S (2020) Design, operation and optimization of constructed wetland for removal of pollutant. Int J Environ Res Public Health 17:8339. https://doi.org/10.3390/ijerph17228339

Rousseau DPL, Lesage E, Story A, Vanrolleghem PA, De Pauw N (2008) Constructed wetlands for water reclamation. Desalination 218(1-3): 181-189. https://doi.org/10.1016/j.desal.2006.09.034

Samsó R, García J (2014) The cartridge theory: a description of the functioning of horizontal subsurface flow constructed wetlands for wastewater treatment, based on modelling results. Sci Total Environ 473-474:651-658. https://doi.org/10.1016/j.scitotenv.2013.12.070

Thalla AK, Devatha CP, Anagh K, Sony E (2019) Performance evaluation of horizontal and vertical flow constructed wetlands as tertiary treatment option for secondary effluents. Appl Water Sci 9:147. https://doi.org/10.1007/s13201-019-1014-9

Turki N, Elaoud A, Gabtni H, Trabelsi I, Khalfallah KK (2019) Agricultural soil characterization using 2D electrical resistivity tomography (ERT) after direct and intermittent digestate application. Arab J Geosci 12:423. https://doi.org/10.1007/s12517-019-4553-3

Vanella D, Cassiani G, Busato L, Boaga J, Barbagallo S, Binley A, Consoli S (2018) Use of small scale electrical resistivity tomography to identify soil-root interactions during deficit irrigation. J Hydrol 556:310-324. https://doi.org/10.1016/j.jhydrol.2017.11.025

Vasconcellos GR, von Sperling M, Ocampos RS (2019) From start-up to heavy clogging: performance evaluation of horizontal subsurface flow constructed wetlands during ten years of operation. Water Sci Technol 79:1231-1240. https://doi.org/10.2166/wst.2019.062

Vymazal J (2010) Constructed wetlands for wastewater treatment. Water 2(3):530-549. https://doi.org/10.3390/w2030530

Vymazal J (2011) Plants used in constructed wetlands with horizontal subsurface flow: a review. Hydrobiologia 674:133-156. https://doi. org/10.1007/s10750-011-0738-9

Vymazal J (2018) Does clogging affect long-term removal of organics and suspended solids in gravel-based horizontal subsurface flow constructed wetlands? Chem Eng J 331:663-674. https://doi.org/ 10.1016/j.cej.2017.09.048

Vymazal J (2019) Is removal of organics and suspended solids in horizontal sub-surface flow constructed wetlands sustainable for twenty and more years? Chem Eng J 378:122117. https://doi.org/10.1016/j. cej.2019.122117

Wang H, Sheng L, Xu J (2021) Clogging mechanisms of constructed wetlands: a critical review. J Clean Prod 295:126455. https://doi. org/10.1016/j.jclepro.2021.126455

Wu H, Zhang J, Ngo HH, Guo W, Hu Z, Liang S, Fan J, Liu H (2015) A review on the sustainability of constructed wetlands for wastewater treatment: design and operation. Bioresour Technol 175:594-601. https://doi.org/10.1016/j.biortech.2014.10.068 